\title{
"Appropriateness of colonoscopy according to EPAGE II in a low resource setting: a cross sectional study from Sri Lanka"
}

\author{
Yasara Samarakoon ${ }^{1}$, Nalika Gunawardena ${ }^{2}$, Aloka Pathirana ${ }^{3}$ and Sumudu Hewage ${ }^{1^{*}}$ (D)
}

\begin{abstract}
Background: Due to finite resources, the clinical decision to subject a patient to colonoscopy needs to be based on the evidence, regardless of its availability, affordability and safety. This study assessed the appropriateness of colonoscopies conducted in selected study settings in Sri Lanka. In the absence of local guidelines, audit was based on European Panel on Appropriateness of Gastrointestinal Endoscopy II (EPAGE II) criteria.

Methods: This cross-sectional study assessed consecutive patients who underwent colonoscopy between June to August 2015 at four main hospitals in Sri Lanka. Interviewer administered questionnaire and secondary data were collected by trained health staff. Indications were assessed according to EPAGE II criteria.

Results: Out of 325 patients, male female proportions were 57.2 and 42.8\%. Mean (SD) age was 54.9 (12.1) years. Colonoscopies were appropriate in 61.2\% (95\% Cl 55.8-66.3), uncertain in 28.6\% (95\% Cl 23.9-33.7) and inappropriate in $10.2 \%$ (95\% Cl 7.3-13.9). Colonoscopy to evaluate abdominal pain has highest percentage of inappropriateness of 10.0\%. However, 9.5\% of these colonoscopies revealed Colo-Rectal Cancer (CRC), reflecting differences in the profile of local CRC patients. Colonoscopies with appropriate or uncertain indications are three times more likely to have a relevant finding than inappropriate indications $(42.5 \%$ vs. $18.2 \%$; OR $3.32,95 \% \mathrm{Cl}$ 1.33-8.3; $P=0.008$ ).

Conclusions: Majority of colonoscopies are appropriate. However, it cannot be neglected that every one in ten patients undergo inappropriate colonoscopy. Proportion of inappropriateness was highest for the indication of chronic abdominal pain, of which, 9.5\% of patients were diagnosed with CRC. This may reflect the different profile of local CRC patients in terms of symptom manifestation and other characteristics. In conclusion, the authors recommend formulation of national guidelines for colonoscopy indications based on current best evidence and local patient profile. Use of such prepared local guidelines will improve the efficient use of finite resources.
\end{abstract}

\section{Background}

Using finite resources to deliver infinite health needs of people is a problem faced by health care decision makers in both Low-Middle and High-Income countries. Clinicians can help to manage this situation better by adhering to evidence-based guidelines in investigating and managing patients. This will ensure the clinician's decisions are effective and efficient. Availability, affordability and safety of an investigation

\footnotetext{
* Correspondence: sumuduavanthi@gmail.com

${ }^{1}$ National Cancer Control Programme, No.555, Public Health Building

Complex, Elvitigala Mawatha, Colombo 5, Sri Lanka

Full list of author information is available at the end of the article
}

are all important but secondary factors that needs to be considered in ordering an investigation.

The frequency of lower endoscopic procedures performed has gradually increased during the last decade [1]. A recent survey in the United States (US) found that the number of colonoscopies performed had risen three to four times between 1998 and 2004 [2]. The pattern in the Europe is found to be similar [3]. Improved efficacy of colonoscopy in colorectal cancer (CRC) screening and quality improvements in some aspects of the procedure like conscious sedation and safety of patients are some of these commonly mentioned reasons for the increase number of colonoscopies in the developed countries [1]. In addition, establishment of open-access endoscopy

(c) The Author(s). 2018 Open Access This article is distributed under the terms of the Creative Commons Attribution 4.0 International License (http://creativecommons.org/licenses/by/4.0/), which permits unrestricted use, distribution, and 
units in the US and Europe where any physician may request an endoscopic procedure is said to have led to an increase in inappropriate referrals and number of endoscopies performed in the western world $[1,4]$.

The European Panel Appropriateness Gastrointestinal Endoscopy (EPAGE-I) was founded in 1999 with the main aim of streamlining the Gastro-Intestinal endoscopies. EPAGE-I criterion contains 12 main indications for colonoscopy, with 309 different clinical scenarios. Each clinical situation is scored from 1 to 9. Scores reflect the appropriateness of the colonoscopy as appropriate 7-9; uncertain 4-6 and inappropriate 1-3 [5]. Updated version of the EPAGE-I criteria has been published recently as EPAGE-II [6]. A clinical validation study done on EPAGE II criteria concluded that significant lesions were more prevalent in appropriate colonoscopies than in those considered inappropriate $(\mathrm{OR}=1.95,95 \% \mathrm{CI}: 1.2-3.1, P<0.005)$ [7]. Application of such criteria reduces the rates of inappropriateness and more importantly, decrease the rate of missed significant lesions [8, 9]. However, it should be noted that these criteria are imperfect, and there is a chance of detecting a significant lesion in about $30 \%$ of inappropriate colonoscopies due to incidental finding of asymptomatic lesions [10].

In Sri Lanka, a national registry is not available for patients who undergo colonoscopies, but data from isolated institutions clearly show an increasing trend. Total number of colonoscopies from the Colombo South Teaching Hospital increased from 785 in 2015 to 947 in year 2016. Absence of studies on evaluation of the appropriateness of colonoscopy published to date in Sri Lanka has left a gap on essential knowledge in the reasons behind the upward trend of colonoscopies in Sri Lanka This gap needs to be fulfilled if we are to improve the cost-effectiveness of the procedure and quality of care, both of which will lead to improved universal health coverage in a country. With this background, we conducted this study to evaluate the appropriateness of colonoscopies performed in selected study settings according to EPAGE-II and to assess predictive factors including appropriateness of the colonoscopy for positive findings.

\section{Methods}

\section{Study settings}

This cross-sectional study was carried out in specialized gastro-intestinal (GI) colonoscopy units at the five main tertiary care hospitals in Sri Lanka. Each of these GI endoscopy unit is under the supervision of one or more consultant gastro-enterologist or general surgeon.

\section{Subjects}

Every consecutive patient who was eligible and underwent colonoscopy during the time period of three months from June 2015 to August 2015 at these study settings was selected. Those who were undergoing regular follow-up colonoscopy, those with incomplete colonoscopies and those with inadequate bowel preparation were excluded. Informed written consent was obtained from all participants while the ethical approval for the study was obtained from the Ethical Review Committee of the University of Colombo under the protocol no EC-15-078.

\section{Data collection}

Information regarding indication of the colonoscopy were obtained from the colonoscopy request forms for out-patients and from the Bed Head Tickets (BHT) for inward patients. In addition, patients were interviewed before the procedure to capture the history of the symptoms and signs and their medical records were used to extract information required for EPAGE criterion. All the information was collected by trained health professionals (medical officers and nurses) using a questionnaire prepared specifically for this study. Study participants were followed up to acquire colonoscopy findings and the histo-pathological diagnosis of the lesions when necessary. This collected information were then fed to evaluate the appropriateness of the clinical decision to subject the patient to colonoscopy according to EPAGE II criterion.

\section{Statistical review}

The main outcome variable of appropriateness of colonoscopy was determined according to the EPAGE II criterion. This criterion classifies appropriateness into 3 categories based on the total marks: appropriate $(\geq 7)$, uncertain (4-6) and inappropriate (>3) [4]. These 'appropriate' and 'uncertain' indications were amalgamated together and were evaluated against 'inappropriate' indications in assessing the associated factors using the Chi squared test. A descriptive analysis was performed on the patients' socio-demographic data, clinical indication of colonoscopy, results of the procedure and histological diagnosis where appropriate. Means and standard errors were used to describe continuous data, while rates and proportions were used for categorical data. Appropriateness level was determined to individual indication. A bivariate analysis was performed for the appropriateness of colonoscopy, dichotomized by the cut-off value of 7on the EPAGE-II scoring system, with patient factors and diagnosis relevance. Differences between groups were assessed using Chi squared test or Fisher's exact test to compare categorical variables. Student's t test or Mann-Whitney U test was used for continuous variables, depending on the normality of their distribution. The level of significance was considered at 5\% 
Table 1 Descriptive data for the study population $(N=325)$

\begin{tabular}{|c|c|c|}
\hline Variable & Number & Percentage (\%) \\
\hline \multicolumn{3}{|l|}{ Sex } \\
\hline Male & 186 & 57.2 \\
\hline Female & 139 & 42.8 \\
\hline \multicolumn{3}{|l|}{ Age } \\
\hline $30-39$ years & 37 & 11.4 \\
\hline $40-49$ years & 69 & 21.2 \\
\hline $50-59$ years & 97 & 29.8 \\
\hline $60-69$ years & 79 & 24.3 \\
\hline$\geq 70$ years & 43 & 13.2 \\
\hline \multicolumn{3}{|l|}{ Race } \\
\hline Sinhala & 290 & 89.2 \\
\hline Tamil & 17 & 5.2 \\
\hline Moor & 16 & 4.9 \\
\hline Burger & 2 & 0.6 \\
\hline \multicolumn{3}{|l|}{ Religion } \\
\hline Buddhism & 210 & 64.6 \\
\hline Hindu & 12 & 3.7 \\
\hline Islam & 16 & 4.9 \\
\hline Christian & 87 & 26.8 \\
\hline \multicolumn{3}{|l|}{ Living area } \\
\hline Urban & 260 & 80.0 \\
\hline Rural & 65 & 20.0 \\
\hline \multicolumn{3}{|l|}{ Educational status } \\
\hline No education & 3 & 0.9 \\
\hline Grade 1- Advanced Level & 225 & 69.2 \\
\hline Advanced Level completed & 69 & 21.2 \\
\hline Technical/Professional/Diploma & 13 & 4.0 \\
\hline University education or above & 15 & 4.6 \\
\hline \multicolumn{3}{|l|}{ Marital status } \\
\hline Unmarried & 27 & 8.3 \\
\hline Married/living together & 262 & 80.6 \\
\hline Marries and living separately & 5 & 1.5 \\
\hline Divorced or widowed & 31 & 9.5 \\
\hline
\end{tabular}

Family history of colorectal cancer among first degree relatives

$\begin{array}{lll}\text { Yes } & 22 & 6.8 \\ \text { No } & 303 & 93.2\end{array}$

Family history of other cancers among first degree relatives

$\begin{array}{lll}\text { Breast cancer } & 14 & 4.3 \\ \text { Ovarian cancer } & 1 & 0.3 \\ \text { Uterine cancer } & 7 & 2.2 \\ \text { Prostate cancer } & 2 & 0.6 \\ \text { Other types of cancers } & 9 & 2.8\end{array}$

Table 1 Descriptive data for the study population $(N=325)$

(Continued)

\begin{tabular}{lll}
\hline Variable & Number & Percentage (\%) \\
\hline Smoking status & & \\
Never actively smoked & 230 & 70.8 \\
Active smoking in the past & 50 & 15.4 \\
Active smoking past and present & 35 & 10.8 \\
Passive smoking only & 10 & 3.1 \\
\hline
\end{tabular}

in all contrasts. Subsequently, multivariate logistic regression was performed to assess variables associated with appropriateness, considering the variables which were identified to be significant at a $p$ value $\leq 0.20$ or clinically relevant variables according to literature as independent variables.

\section{Results}

We could achieve a 100\% response rate from patients from both state and private sector patients. A total of 325 colonoscopies were included over the study period out of which, 239 (73.5\%) were from state hospitals and $86(26.4 \%)$ were from the private hospital. The study group consisted of 186 (57.2\%) males and 139 (42.8\%) females. The mean (SD) age was 54.9 (12.1). Percentage who has never actively smoked was $70.8 \%$, while $66.5 \%$ had never taken alcohol. None was follow-up colonoscopies for diagnosed CRC patients while 22 (6.8\%) patients had a family history of CRC among the first degree relatives. Family history of Breast cancer, Ovarian cancer and Uterine cancer were reported in 14 (4.3\%), 1 $(0.3 \%)$ and $7(2.2 \%)$ of patients. The descriptive data for the study population is shown in Table 1.

Among the 325 patients who underwent colonoscopy, three commonest indications were rectal bleeding $(n=110,33.8 \%)$, change in bowel habits $(n=79$, 24.3\%) and unexplained chronic abdominal pain $(n=61$, $18.8 \%)$ sequentially. Half of colonoscopies $(n=168,51.7 \%)$ ended up as normal studies. Polyps were detected and sampled in $98(30.1 \%)$ patients, but none of them were diagnosed as adenomatous polyps histologically. Therefore, all polyps were categorized under normal study. Table 2 displays colonoscopy findings against the indication.

As detailed in Table 3, colonoscopies were evaluated as appropriate in $61.2 \%$ of the patients (95\% CI 55.8-66.3), uncertain in $28.6 \%$ (95\% CI 23.9-33.7) and inappropriate in $10.2 \%$ (95\% CI $7.3-13.9)$ according to EPAGE II criteria. Rectal bleeding and changes in bowel habits were the symptoms which presented the highest percentage of appropriateness, 65.0 and 30.0\%respectively, while lump at anus presented the lowest appropriateness of $0.0 \%$. Abdominal pain rescored the highest percentage of inappropriateness of $9.5 \%$, as a symptom for colonoscopy. $89.7 \%$ of opportunistic screening was appropriate 
Table 2 Colonoscopy findings against the indication $(N=325)$

\begin{tabular}{|c|c|c|c|c|c|c|}
\hline \multicolumn{7}{|l|}{ Colonoscopy finding } \\
\hline & $\begin{array}{l}\text { Normal study } \\
n(\%)\end{array}$ & $\begin{array}{l}\text { Colo-rectal Carcinoma } \\
n(\%)\end{array}$ & $\begin{array}{l}\text { Haemorrhoides } \\
n(\%)\end{array}$ & $\begin{array}{l}\text { Anal fissure } \\
n(\%)\end{array}$ & $\begin{array}{l}\text { Diverticular disease } \\
n(\%)\end{array}$ & $\begin{array}{l}\text { Total } \\
n(\%)\end{array}$ \\
\hline \multicolumn{7}{|c|}{ Indication for colonoscopy } \\
\hline Rectal bleeding & $52(16.0)$ & $58(17.8)$ & $19(5.8)$ & $0(0.0)$ & $1(0.3)$ & $130(40.0)$ \\
\hline Altered bowel habits & $56(17.2)$ & $34(10.5)$ & $2(0.6)$ & $0(0.0)$ & $0(0.0)$ & $92(28.3)$ \\
\hline Abdominal pain & $39(12.0)$ & $31(9.5)$ & $4(1.2)$ & $0(0.0)$ & $0(0.0)$ & $74(22.8)$ \\
\hline Screening & $19(5.8)$ & $5(1.5)$ & $0(0.0)$ & $0(0.0)$ & $0(0.0)$ & $24(7.4)$ \\
\hline Lump at anus & $1(0.3)$ & $0(0.0)$ & $2(0.6)$ & $1(0.3)$ & $0(0.0)$ & $4(1.2)$ \\
\hline Loss of weight & $1(0.3)$ & $0(0.0)$ & $0(0.0)$ & $0(0.0)$ & $0(0.0)$ & $1(0.3)$ \\
\hline Total n (\%) & $168(51.7)$ & $128(39.4)$ & $27(8.3)$ & $1(0.3)$ & $1(0.3)$ & $325(100.0$ \\
\hline
\end{tabular}

according to EPAGE criteria, while $6.5 \%$ were uncertain and $3.7 \%$ were inappropriate. Appropriateness of colonoscopy significantly increased in relation to age from $52.6 \%$ in patients more than 50 years of age to $8.6 \%$ in patients less or equal to 50 years of age (chi square $89.5 ; p<0.001$ ). Appropriateness was also evaluated for symptomatic against screening colonoscopies. The clinical decision to subject some symptomatic patients to colonoscopy was the clinician's opinion of the risk of the patient for CRC being high rather than the symptom. Such patients identified through their medical records and were categorized under the 'opportunistic screening' category rather than the 'symptomatic category'. This resulted in total of opportunistic screening colonoscopies to be 107 (32.9\%) in the Table 4, as opposed to 24 (7.4\%) in the Table 3. Indication being symptomatic was significantly associated with appropriate colonoscopy rather than opportunistic screening $(p<0.001)$. Classification of colonoscopy appropriateness according to EPAGE II criteria against selected characteristics is shown in Table 3, while the factors associated with appropriate colonoscopy according to EPAGE II criteria is shown in Table 4.

Multivariate logistic regression revealed that appropriateness of colonoscopy was significantly associated with the age being more than 50 years $(\mathrm{OR}=8.5 ; p<0.001$; 95\% CI 4.9-14.8). One out of the five institutions, the National Hospital of Sri Lanka, was also found to be significantly associated with the appropriateness of colonoscopy $(22 \mathrm{OR}=2.7 ; p=0.18,95 \%$ CI 1.2-6.2). Sex of the patient or the indication of colonoscopy being screening or symptomatic was not significantly associated with the appropriateness according to EPAGE II criteria.

Table 3 Classification of colonoscopy appropriateness according to the EPAGE II criteria against selected characteristics of the patient and indication. EPAGE II criteria percentages for each factor are shown per row

\begin{tabular}{|c|c|c|c|c|c|}
\hline & & Classification acco & to EPAGE criter & & \\
\hline & $\begin{array}{l}\text { Total } \\
N=325(\%)\end{array}$ & $\begin{array}{l}\text { Inappropriate } \leq 3 \\
n=33(10.2 \%)\end{array}$ & $\begin{array}{l}\text { Uncertain 4-6 } \\
n=93(28.6 \%)\end{array}$ & $\begin{array}{l}\text { Appropriate } \geq 7 \\
n=199(61.2 \%)\end{array}$ & $p$ value \\
\hline Age & & & & & $<0.001$ \\
\hline$\leq 50$ years & $102(31.4)$ & $29(28.4)$ & $45(44.1)$ & $28(27.4)$ & \\
\hline$>50$ years & $223(68.6)$ & $4(1.8)$ & $48(21.5)$ & $171(76.6)$ & \\
\hline Sex & & & & & 0.41 \\
\hline Women & $163(50.1)$ & 19 (11.6) & $42(25.7)$ & $102(62.6)$ & \\
\hline Men & $162(49.9)$ & $14(8.6)$ & $51(31.5)$ & $97(59.9)$ & \\
\hline Type of colonoscopy & & & & & $<0.001$ \\
\hline Symptomatic & $218(67.0)$ & $27(12.4)$ & $86(39.4)$ & $103(47.2)$ & \\
\hline Screening & $107(32.9)$ & $4(3.7)$ & $7(6.5)$ & $96(89.7)$ & \\
\hline Indication for symptomatic colonoscopies $(n=218)$ & & & & & $<0.001$ \\
\hline Rectal bleeding & $96(44.0)$ & $4(4.1)$ & $25(26.0)$ & $67(69.8)$ & \\
\hline Altered bowel habits & $44(20.2)$ & $4(9.0)$ & $9(20.4)$ & $31(70.4)$ & \\
\hline Abdominal pain & $31(14.2)$ & $10(32.2)$ & $21(65.6)$ & $0(0.0)$ & \\
\hline Other & $47(21.5)$ & $11(23.4)$ & $31(65.9)$ & $5(10.6)$ & \\
\hline
\end{tabular}


Table 4 Factors associated with appropriate colonoscopy according to EPAGE II criteria

\begin{tabular}{llll}
\hline Factor & OR & $95 \%$ Confidence interval for OR & $P$ value \\
\hline $\begin{array}{l}\text { Age } \\
\quad 50 \text { years }\end{array}$ & 8.52 & $\mathbf{4 . 9 0 - 1 4 . 8 2}$ & \\
$\quad<50$ years & & & \\
Sex & & & \\
$\quad$ Male & 0.95 & $0.56-1.58$ & 0.835 \\
$\quad$ Female & & & \\
Institution & & & .881 \\
NCIM & .951 & $0.49-1.83$ & .018 \\
NHSL & 2.727 & $\mathbf{1 . 1 9 - 6 . 2 4}$ & .595 \\
CSTH & .653 & $0.13-3.14$ & .862 \\
CNTH & 1.076 & $0.47-2.46$ & \\
Private Hospital & & & \\
\hline
\end{tabular}

NCIM - National Cancer Institute - Maharagama

NHSL - National Hospital of Sri Lanka

CSTH - Colombo South Teaching Hospital

CNTH - Colombo North Teaching Hospital

95\% Confidence Interval are in bold

\section{Discussion}

Every single unnecessary investigation or procedure is afforded at the cost of another necessary health service or an item. Limiting investigations to those who require it also helps to reduce the work load of the health care team, which will in return lead to improvement in the quality of care and low cost. EPAGE II is a valid set of criteria which has been shown to be valid to identify appropriate gastrointestinal endoscopy $[6,11,12]$.

Rectal bleeding ranked number one as the indication for colonoscopy $(n=130 ; 40 \%)$, followed by altered bowel habits $(n=92 ; 28.3 \%)$ and abdominal pain $(n=74$; $22.8 \%$ ). These indications were similar to common indications found in other European studies as well [12-14]. However, opportunistic screening for CRC was done only in 24 (7.4\%) out of the 325 studied. Half of colonoscopies (51.7\%) were normal studies, while colorectal carcinoma was found in $39.4 \%$ and haemorrhoides in $8.3 \%$ of study participants. Out of 128 patients who were diagnosed to have CRC, 58 (17.8\%) had presented with rectal bleeding, 34 (10.5\%) with altered bowel habits and 31 (9.5\%) with abdominal pain. Only 5 (1.5\%) of CRC patients were detected through opportunistic screening.

The majority of the indications for colonoscopy are appropriate according to the EPAGE II criteria (61.2, 95\% CI 55.8-66.3\%). However, it should be noted that $28.6 \%$ (95\% CI 23.9-33.7\%) of uncertain and 10.2\% (95\% CI 7.3-13.9\%) of inappropriate criteria cannot be neglected. Studies from all over the world have reported percentages within the range of for appropriateness of colonoscopy. Highest reported thus far according to EPAGE II evaluation is $80.4 \%$ [14], while the lowest (26\%) is recorded from a multi-country study which involved 21 endoscopy centers from 11 countries [15]. One study from Ivory Coast, Africa found out an appropriateness percentage to be $40 \%$ [16], which is below our finding. Scarcity of regional and local literature seriously hinders evaluating the position of Sri Lanka relative to other South Asian countries which are socio-economic and health system wise similar. However, our study finding of appropriateness of colonoscopy according to EPAGE II criteria of 61. $2 \%$ is in par with the findings from most European studies [16-18]. But when the proportions of inappropriateness are considered, values as high as $27 \%$ have been reported in a multicentric study in 11 European countries [16]. European countries which show higher percentages of inappropriate indications than that from our study include Switzerland at 13-27\% [19, 20-22] and Spain at 23$31 \%$ [22]. However, this proportions have improved after 2009, when the evaluation is done using EPAGE II criteria. Spanish studies conducted after 2009 records a percentage of $10.5-17.5 \%$ inappropriate colonoscopy $[13,23]$, which is similar to this study. Even though the percentage estimated by this study is low, the number cannot be neglected when the cost borne by the health system for a colonoscopy is considered. Based on this evidence, the clinicians need to consider the indication for colonoscopy more carefully.

Likewise, symptomatic colonoscopy was found to be more appropriate than opportunistic screening colonoscopies $(p=<0.001)$. As described previously, opportunistic screening group consisted of patients who were subjected to colonoscopies purely for screening purposes without any symptom and also symptomatic patients. The clinical decision to subject this proportion of symptomatic patients to colonoscopy not being their symptom per se, but also the clinician's opinion that the patient was at high risk of developing CRC was the rationale to include them in the opportunistic screening category even though they presented with symptoms. This significant association strengthen the evidence of subjecting a patient to colonoscopy based on guidelines.

Out of the 218 symptomatic colonoscopies, more than half had been performed to evaluate rectal bleeding (40.4\%) and altered bowel habits (20.2\%), with least percentages of inappropriateness of 4.1 and $9.0 \%$ respectively. In contrast, abdominal pain assessment through colonoscopy does not seem to be very useful according to EPAGE II. Total of 31 colonoscopies done to assess chronic abdominal pain is categorized as inappropriate in $32.2 \%(n=10)$ and the rest $21(65.5 \%)$ fell into uncertain category. None of the colonoscopy was graded as appropriate (Table 3). However, results of $9.2 \%$ of colonoscopies performed to evaluate chronic abdominal pain have turned out to be CRC, which is a higher proportion compared to other studies $(7,8)$. This might indicate 
that some presenting symptoms of CRC patients in Sri Lanka can be different to well recognized symptoms. Therefore, it is important that characteristics of local patient population is systematically studied, especially with regard to their symptom profile, and local indications for colonoscopy are adjusted to suit the local epidemiological picture. Future research should explore more on this avenue and the findings should be used in making local guidelines for colonoscopy indications. Use of such local guidelines which are formulated based on local epidemiological and symptom profile would be more suitable in auditing colonoscopy appropriateness in Sri Lanka rather than using international guidelines. However, limitations inherited to cross-sectional studies in an out-patient clinic set-up like inability to randomly assign patients, which could introduce a selection bias, should be borne in mind in planning future studies.

Patients with appropriate or uncertain indications based on EPAGE II criteria are found to be three times more likely of having a relevant colonoscopy finding than those with inappropriate indications (42.5\% vs. $18.2 \%$; OR 3.32, 95\% CI 1.33-8.3; $P=0.008$ ). This evidence strongly suggests that adherence to guidelines in performing colonoscopies is more likely to improve efficient use of limited resources, while improving patient safety and the quality of the health services delivered to the patients.

\section{Abbreviations}

BHT: Bed Head Ticket; CRC: Colo-Rectal Cancer; EPAGE: European Panel on Appropriateness of Gastrointestinal Endoscopy; Gl: Gastro-intestinal

\section{Acknowledgements}

Our sincere gratitude extends to the directors of the hospitals and clinicians who facilitated the study by granting permissions to contact patients and study settings. All the study participants are remembered with respect. The authors wish to thank the health staff who was involved in the study as data collectors as well.

\section{Ethics approval and consent to participation}

The ethical approval for this study was obtained from the Ethical Review Committee, University of Colombo under the protocol number EC-15-078. All study participants were well informed regarding the purpose and the nature of the study and voluntary written consent was obtained prior to data collection.

\section{Funding}

This study received a grant of Rs.500,000.00 from the Medical Research Institute - Sri Lanka, which is a governmental organization under the grant number 2015/025.

\section{Availability of data and materials}

The dataset which was used to generate information for this study is not available publicly. Nor it cannot be shared with the journal as it contains details of cancer patients which can be traced back to personal level. The authors regret any inconvenience caused by not being able to share the data set, but the study participants consented to participate with the knowledge that their information will not be shared with a third party for any reason.

\section{Authors' contributions}

Conceptualization, YS and N; Methodology, SAH, YS and NG; Validation, NG and AP; formal analysis, SAH; Investigation, YS; Writing - Original draft, SAH and YS; Writing - Review and Editing, NG and AP; Supervision, NG and AP. All authors have read and approved the final version of the manuscript.

\section{Competing interests}

The authors declare that they have no competing of interests.

\section{Publisher's Note}

Springer Nature remains neutral with regard to jurisdictional claims in published maps and institutional affiliations.

\section{Author details}

${ }^{1}$ National Cancer Control Programme, No.555, Public Health Building Complex, Elvitigala Mawatha, Colombo 5, Sri Lanka. ${ }^{2}$ World Health Organization Country Office for Sri Lanka, No. 5, Anderson road, Colombo 5, Sri Lanka. ${ }^{3}$ Department of surgery, Faculty of Medical Sciences, University of Sri Jayewardenepura, Sri Jayewardenepura, Sri Lanka.

Received: 10 January 2018 Accepted: 11 May 2018

Published online: 29 May 2018

\section{References}

1. Gimeno-García AZ, Quintero E. Colonoscopy appropriateness: really needed or a waste of time? World J Gastrointest Endosc. 2015;7(2):94-101. https://doi.org/10.4253/wjge.v7.i2.94.

2. Sonnenberg A, Amorosi SL, Lacey MJ, Lieberman DA. Patterns of endoscopy in the United States: analysis of data from the Centers for Medicare and Medicaid Services and the National Endoscopic Database. Gastrointest Endosc. 2008:67(3):489-96.

3. Heuss LT, Froehlich F, Beglinger C. Changing patterns of sedation and monitoring practice during endoscopy: results of a nationwide survey in Switzerland. Endoscopy. 2005;37(2):161-6.

4. Mahajan RJ, Barthel JS, Marshall JB. Appropriateness of referrals for openaccess endoscopy. How do physicians in different medical specialties do? Arch Intern Med. 1996 Oct 14;156(18):2065-9.

5. American Society for Gastrointestinal Endoscopy. Appropriate use of gastrointestinal endoscopy. Gastrointest Endosc. 2000:52:831-7.

6. Juillerat P, Peytremann-Bridevaux I, Vader JP, Arditi C, Schusselé Filliettaz S, Dubois RW, Gonvers JJ, Froehlich F, Burnand B, Pittet V. Appropriateness of colonoscopy in Europe (EPAGE II). Presentation of methodology, general results, and analysis of complications. Endoscopy 2009; 41: 240-246 [PMID: 19280536].

7. Gimeno García AZ, González Y, Quintero E, Nicolás-Pérez D, Adrián Z, Romero R, Alarcón Fernández O, Hernández M, Carrillo M, Felipe V, Díaz J, Ramos L, Moreno M, Jiménez-Sosa A. Clinical validation of the European panel on the appropriateness of gastrointestinal endoscopy (EPAGE) II criteria in an open access unit: a prospective study. Endoscopy. 2012:44:32-7.

8. Argüello L, Pertejo V, Ponce M, Peiró S, Garrigues V, Ponce J. The appropriateness of colonoscopies at a teaching hospital: magnitude, associated factors, and comparison of EPAGE and EPAGE-II criteria. Gastrointest Endosc. 2012;75:138-45.

9. Eskeland SL, Dalén E, Sponheim J, Lind E, Brunborg C, de Lange T. European panel on the appropriateness of gastrointestinal endoscopy II guidelines help in selecting and prioritizing patients referred to colonoscopy - a quality control study. Scand J Gastroenterol. 2014;49(4):492-500. https://doi. org/10.3109/00365521.2014.886715

10. Hassan C, Di Giulio E, Marmo R, Zullo A, Annibale B. Appropriateness of the indication focolonoscopy: systematic review and meta-analysis. J Gastrointestin Liver Dis. 2011;20:279-86.

11. European Panel on the Appropriateness of Gastrointestinal endoscopy II. Institute for Social and Preventive Medecine - Division of gastroenterology \& Hepatology. Copyright (@) 2008 IUMSP / CHUV, Lausanne: Disponible en; http://epage.ch/. Accessed 04 June 2008.

12. Garcia AZG, Gonzalez Y, Quintero E, Nicolas-Perez D, Adrian Z, Romero R, et al. Clinical validation of the European Panel on the Appropriateness of Gastrointestinal Endoscopy (EPAGE) II criteria in an open-access unit: a prospective study.

13. Marzo-Castillejo M, Almeda J, Mascort JJ, Cunillera O, Saladich R, Nieto R, Piñeiro P, Llagostera M, Cantero FX, Segarra M, Puente D. Appropriateness of colonoscopy requests according to EPAGE-II in the Spanish region of 
Catalonia. BMC Family Practice. 2015;16:15. available at https://bmcfampract. biomedcentral.com/articles/10.1186/s12875-015-0369-8

14. Burnand B, Harris JK, Wietlisbach V, Froehlich F, Vader JP, Gonvers JJ. Use, appropriateness and diagnostic yield of screening colonoscopy: an international observational study (EPAGE). Gastrointest Endosc. 2006;63(7):1018-26.

15. Assi C, Lohouse-Kouacou MJ, Allah-Kouadio E, Njossu CJ, Okon AJB, Doffou $S$, et al. Appropriateness of colonoscopy in Cocody teaching hospital in 2010: a prospective study using criteria established by the European panel on the appropriateness of gastrointestinal endoscopy (EPAGE). Open journal of Gastroenterology. 2012;2:193-9.

16. Harris JK, Froehlich F, Gonvers JJ, Wietlisbach V, Burnand B, Vader JP. The appropriateness of colonoscopy: a multi-center, international, observational study. Int J Qual Health Care. 2007;19:150-7.

17. Terraz O, Wietlisbach V, Jeannot JG, Burnanda B, Froehlich F, Gonvers JJ, et al. The EPAGE internet guideline as a decision support tool for determining the appropriateness of colonoscopy. Digestion. 2005;71:72-7.

18. Burnand B, Harris JK, Wietlisbach V, Froehlich F, Vader JP, Gonvers JJ. Use, appropriateness, and diagnostic yield of screening colonoscopy: an international observational study (EPAGE). Gastrointest Endosc. 2006;63: $1018-26$.

19. Gonvers JJ, Harris JK, Wietlisbach V, et al. A European view of diagnostic yield and appropriateness of colonoscopy. Journal of. HepatoGastroenterology. 2007;54:729-35.

20. Balaguer F, Llach J, Castells A, Bordas JM, Pellisé M, Rodriguez-Moranta F, et al. The European panel on the appropriateness of gastrointestinal endoscopy guidelines colonoscopy in an open-access endoscopy unit: a prospective study. Aliment Pharmacol Ther. 2005;21:609-13.

21. Fernández-Esparrach $G$, Gimeno-García $A Z$ Z, Llach J, Pellisé $M$, Ginès $A$, Balaguer F, et al. Recomendaciones de utilización de la endoscopia: análisis de la probabilidad de encontrar lesiones significativas en los pacientes procedentes de la atención extrahospitalaria. Med Clin (Barc). 2007:129:205-8

22. Carrión S, Marín I, Lorenzo-Zuñiga V, Moreno-De Vega V, Boixa J. Adecuación de la indicación de la colonoscopia según los nuevos criterios de EPAGE II. Gastroenterol Hepatol. 2010;33:484-9.

23. Schusselé Filliettaz S1, Gonvers JJ, Peytremann-Bridevaux I, Arditi C, Delvaux M, Numans ME, Lorenzo-Zúñiga V, Dubois RW, Juillerat P, Burnand B, Pittet $\checkmark$, Vader JP, Froehlich F; EPAGE II Study Group. Appropriateness of colonoscopy in Europe (EPAGE II). Functional bowel disorders: pain, constipation and bloating. Endoscopy. 2009 Mar;41(3):234-9. https://doi.org/ 10.1055/s-0028-1119625.

Ready to submit your research? Choose BMC and benefit from:

- fast, convenient online submission

- thorough peer review by experienced researchers in your field

- rapid publication on acceptance

- support for research data, including large and complex data types

- gold Open Access which fosters wider collaboration and increased citations

- maximum visibility for your research: over $100 \mathrm{M}$ website views per year

At BMC, research is always in progress.

Learn more biomedcentral.com/submissions 